\title{
ANALISIS PENGEMBANGAN OBYEK WISATA ALAM DI RESORT BALIK BUKIT TAMAN NASIONAL BUKIT BARISAN SELATAN
}

\section{(ANALYSIS OF THE DEVELOPMENT OF NATURE TOURISM IN BALIK BUKIT RESORT BUKIT BARISAN SELATAN NATIONAL PARK)}

\author{
Meizannur dan Christine Wulandari \\ Jurusan Kehutanan Fakultas Pertanian Universitas Lampung \\ J1. Prof. Dr. Sumantri Brojonegoro No. 1 Bandar Lampung, 35143, Lampung \\ E-mail : meizannur@ymail.com, No Telepon : 085367201481/082183354521
}

\begin{abstract}
ABSTRAK
Taman Nasional Bukit Barisan Selatan (TNBBS) merupakan kawasan pelestarian alam yang memiliki banyak potensi, baik flora, fauna maupun obyek wisata alam yang memiliki nilai kealamian yang tinggi. Salah satu Resort yang saat ini dikembangkan obyek wisata alamnya adalah Resort Balik Bukit. Penelitian ini bertujuan: (1) mengetahui potensi sumberdaya wisata alam di Resort Balik Bukit, (2) mengetahui potensi sumberdaya manusia yang ada di sekitar Resort Balik Bukit, (3) mengetahui manajemen yang dilakukan dalam pengembangan obyek wisata alam Resort Balik Bukit, dan (4) merumuskan strategi pengembangan obyek wisata alam Resort Balik Bukit TNBBS. Penelitian dilakukan selama 3 bulan, mulai dari Januari - Maret 2013. Pengumpulan data dilakukan melalui pengamatan langsung di lapangan, wawancara, dan studi pustaka. Analisis data dilakukan dengan 2 cara yaitu analisis deskriptif dan SWOT dengan menghitung bobot dan rating dari EFAS dan IFAS. Hasil penelitian menunjukkan Resort Balik Bukit TNBBS memiliki potensi wisata yang menarik bagi pengunjung seperti Air Terjun, Sungai Way Sepapa, Ekosistem Hutan Pegunungan Bawah, Flora dan Fauna, Pemandagan Alam, dan Batu berbentuk balok. Potensi di sekitar Resort Balik Bukit yang mendukung kegiatan pengembangan adalah kemampuan masyarakat membuat kerajinan tangan. Pengelolaan obyek wisata alam Resort Balik Bukit dilakukan oleh TNBBS mulai dari perencanaan, pengorganisaian, pelaksanaan, dan pengawasan, namun pengembangan yang dilakukan masih kurang optimal dan tidak ada para pihak lain yang terlibat. Berdasarkan hasil penelitian strategi paling utama yang bisa diterapkan pihak Balai Besar TNBBS adalah mempromosikan potensi yang ada di Resort Balik Bukit ke pasar wisata dan menjalin kerjasama dengan para pihak sehingga pengembangan obyek wisata alam Resort Balik Bukit dapat menjadi lebih baik.
\end{abstract}

Kata kunci: Potensi wisata alam, analisis SWOT, Balai Besar Taman Nasional Bukit Barisan Selatan, Resort Balik Bukit

\section{ABSTRACT}

Taman Nasional Bukit Barisan Selatan (TNBBS) is a nature conservation area which has a lot of potential, flora, fauna and natural attractions that have a high value of naturalness. One of the resorts that were recently developed tourist attraction is its natural Resort Balik Bukit. This study aims to: (1) determine the resource potential of nature in Resort Balik Bukit, (2) determine the potential of human resources that exist around the Resort Balik Bukit, (3) determine that management made in the development of natural attractions Behind Hill Resort, and (4) formulating development strategies of natural attractions Resort Balik Bukit TNBBS. The study was conducted for 3 months, from January to March 2013. Data collected through direct observation, interviews, and literature. Data analysis was done in 2 ways descriptive analysis and SWOT by calculating the weight and rating of EFAS and IFAS. The 
results showed Resort Balik Bukit TNBBS has tourism potential interest to visitors such as Waterfall, River Way Sepapa, Lower Mountains Forest Ecosystem, Flora and Fauna, Nature landscape, and Stone shaped beam. Potential around the Resort Balik Bukit that support community development activities is the ability to make crafts. Management of natural attractions Resort Balik Bukit performed by TNBBS ranging from planning, organizing, implementation, and supervision, but the development is still less than optimal conducted and no other parties are involved. Based on the research results of the most important strategies that can be applied to the Great Hall TNBBS is promoting potentials in Resort Balik Bukit to the tourist market and cooperated with the parties so that the development of natural attractions Resort Balik Bukit can be better.

Keywords: Potential of Nature Tourism, SWOT Analysis, Taman Nasional Bukit Barisan Selatan, Resort Balik Bukit

\section{PENDAHULUAN}

Taman Nasional Bukit Barisan Selatan (TNBBS) merupakan salah satu kawasan pelestarian alam yang memiliki banyak potensi, baik flora maupun fauna yang tergolong langka. Salah satu potensi TNBBS yang dapat dikembangkan adalah obyek wisata alam di Resort Balik Bukit Pekon Kubu Perahu TNBBS. Potensi yang dapat dikembangkan seperti Air Terjun Sepapa Kiri, Air Terjun Sepapa Kanan, Air Terjun Way Asahan, Sungai yang mengalir dari dalam kawasan, Ekosistem Hutan Hujan Pegungnungan Bawah, Flora dan Fauna, Pemandangan Alam dari ketinggian, dan keunikan Batu yang berbentuk balok yang memiliki daya tarik bagi pengujung (Balai Besar Taman Nasional Bukit Barisan Selatan, 2007).

Saat ini kecenderungan wisatawan untuk melakukan aktifitas di alam terbuka semakin meningkat dengan demikian perlu upaya pengembangan yang lebih baik agar potensi Resort Balik Bukit dapat lebih diminati oleh para wisatawan. Potensi sumberdaya wisata Resort Balik Bukit cukup besar namun belum diiringi dengan pengelolaan yang optimal, sehingga diperlukan sebuah strategi mengenai pengembangan secara optimal berdasarkan atas asas kelestarian.

Penelitian ini dilakukan bertujuan untuk mengetahui potensi sumberdaya wisata alam di Reosrt Balik Bukit, potensi sumberdaya manusia yang terdapat di Resort Balik Bukit, mengetahui manajemen yang dilakukan dalam pengembangan obyek wisata alam Resort Balik Bukit dan merumuskan strategi pengembangan obyek wisata alam Resort Balik Bukit Pekon Kubu Perahu. Hasil dari penelitian ini diharapkan dapat menjadi bahan masukan bagi pihak pengelola dalam pengelolaan dan pengembangan obyek wisata alam di Resort Balik Bukit.

\section{METODE PENELITIAN}

Penelitian dilaksanakan di Resort Balik Bukit TNBBS pada bulan Januari - Maret 2013. Alat yang digunakan berupa alat tulis, komputer, kamera, peta, dan kuesioner. Obyek penelitian ini adalah masyarakat yang berada di sekitar Resort Balik Bukit, pengunjung dan pihak pengelola Resort Balik Bukit. Data yang digunakan dalam penelitian ini terdiri dari data primer dan data sekunder.

Data primer meliputi karakteristik responden, potensi sumberdaya wisata alam dan sumberdaya manusia, persepsi dan keinginan masyarakat Balik Bukit terhadap pengembangan obyek wisata alam, minat, persepsi dan motivasi pengunjung terhadap pengembangan obyek wisata alam dan informasi dari staff TNBBS, yang diteliti meliputi: aspek perencanaan, pengorganisasian, pelaksanaan dan pengawasan. Data primer dikumpulkan dengan 
wawancara menggunakan kuesioner yang disiapkan dan observasi pada areal penelitian. Data sekunder meliputi kondisi umum lokasi penelitian, peta, dan masterplan pengembangan obyek wisata alam di TNBBS, data sekunder diperoleh dengan mengumpulkan dokumen dari Pihak TNBBS.

Penentuan responden pada masyarakat dihitung menggunakan rumus Arikunto (2002) :

$$
\begin{aligned}
& n=\frac{\mathrm{N}}{\mathrm{N}\left(e^{2}\right)+1} \\
& n=\frac{576}{576\left(0,1^{2}\right)+1} \\
& n=\frac{576}{6,76} \\
& n=85,2 \\
& n=85
\end{aligned}
$$

Keterangan : $\mathrm{n}:$ Jumlah responden

$\mathrm{N}$ : Jumlah total kepala keluarga $(\mathrm{KK})$ yang menjadi sampel

e : Presisi $10 \%$

1 : Bilangan konstan

Diperoleh jumlah responden pada tingkat masyarakat sebanyak 85 responden dari total 576 KK Pekon Balik Bukit. Setelah didapat jumlah responden untuk pengambilan sampel yang diwawancara dilakukan secara purposive sampling. Selanjutnya pengambilan sampel pada tingkat pengunjung dilakukan dengan wawancara. Penentuan sampel pengunjung dihitung dengan rumus Arikunto (2002) :

$$
\begin{aligned}
& n=\frac{\mathrm{N}}{\mathrm{N}\left(e^{2}\right)+1} \\
& n=\frac{1.752}{1.752\left(0,1^{2}\right)+1} \\
& n=\frac{1.752}{18,52} \\
& n=94 \text {, }
\end{aligned}
$$

Diperoleh jumlah sampel pengunjung pada obyek wisata alam Resort Balik Bukit Pekon Kubu Perahu sebanyak 94 responden dari total 1.752 orang jumlah pengunjung selama 3 tahun. Penentuan sampel pengunjung dilakukan secara random sampling, karena pengunjung tidak datang setiap hari. Jumlah pengunjung obyek wisata alam Resort Balik Bukit tahun $2010-2012$.

Tabel 1. Jumlah pengunjung obyek wisata alam Resort Balik Bukit tahun 2010 - 2012.

\begin{tabular}{cccc}
\hline Tahun & Nusanatara & Mancanegara & Jumlah \\
\hline $\mathbf{2 0 1 0}$ & 217 & 74 & 291 \\
$\mathbf{2 0 1 1}$ & 254 & 96 & 350 \\
$\mathbf{2 0 1 2}$ & 963 & 148 & 1.111 \\
\hline TOTAL & $\mathbf{1 . 4 3 4}$ & $\mathbf{3 1 8}$ & $\mathbf{1 . 7 5 2}$ \\
\hline
\end{tabular}

Sumber : SPTN III Liwa, 2012.

Responden untuk staff Balai Besar TNBBS adalah Kepala Bidang Pengelolaan Taman Nasional Wilayah II Liwa, Kepala Seksi Pengelolaan Taman Nasional Wilayah III Krui, Kepala Resort Balik Bukit, dan 1 Pengendali Ekosistem Hutan. Analisis data dilakukan dengan menggunakan dua metode yaitu deskriptif kualitatif dan SWOT (Rangkuti, 2006). Analisis deskriptif kualitatif dilakukan untuk menganilisis data mengenai potensi wisata alam Resort Balik Bukit, potensi sumberdaya manusia di sekitar Resort Balik Bukit, dan aspek 
manajemen obyek wisata alam Resort Balik Bukit. Setelah dilakukan analisis deskriptif kualitatif selanjutnya dilakukan analisis yang lebih lanjut dengan menggunakan SWOT untuk menyusun perencanaan pengembangan obyek wisata alam di Resort Balik Bukit Pekon Kubu Perahu. Analisis SWOT dilakukan untuk menentukan strategi pengembangan obyek wisata alam di Resort Balik Bukit Pekon Kubu Perahu.

Penentuan faktor-faktor strategis internal dan eksternal dilakukan berdasarkan keadaan di lapangan, selanjutnya dilakukan penyusunan faktor-faktor strategis eksternal dan internal dalam matrik SWOT. Setelah penyusunan faktor strategis eksternal dan internal dilakukan kemudian menentukan bobot dan rating berdasarkan tabel IFAS dan EFAS dari masingmasing faktor. Bobot dan rating ditentukan berdasarkan tingkat nilai penting dari faktorfaktor tersebut dan berdasarkan diskusi dengan Kepala Bidang Pengelolaan Taman Nasional Wilayah II Liwa, Kepala Seksi Pengelolaan Taman Nasional Wilayah III Krui, Kepala Resort Balik Bukit, dan 1 orang Pengendali Ekosistem Hutan.

Selanjutnya untuk menentukan skor dari masing-masing faktor dilakukan dengan mengalikan antara bobot dengan rating sehingga dihasilkan skor dari setiap faktor. Matrik SWOT dari penyusunan strategis eksternal dan internal serta analisis SWOT tersebut muncul 4 (empat) strategi, yaitu strategi SO, ST, WO dan WT. Kemudian menentukan prioritas strategi yang lebih diutamakan dengan cara menjumlahkan nilai kode pembobotan dari setiap strategi yang telah ditentukan dalam matrik SWOT sehingga diperoleh total skor terbesar yang dapat dijadikan prioritas paling utama.

\section{HASIL DAN PEMBAHASAN}

\section{Persepsi dan motivasi Para Pihak terhadap pengembangan obyek wisata alam Resort Balik Bukit}

\section{Masyarakat}

Menurut hasil wawancara, 89\% masyarakat mengatakan Resort Balik Bukit mempunyai potensi wisata yang baik dan menarik sehingga layak untuk dikembangkan. Dalam kegiatan pengembangan, $80 \%$ masyarakat menyatakan bahwa masih perlu perbaikan pada fasilitasfasilitas wisata yang sudah rusak dan perlu penambahan sarana prasarana wisata seperti pengadaan tempat penjualan souvenir dan penginapan bagi pengunjung.

Sebanyak 99\% masyrakat yang berdomisili di Kubu Perahu memiliki keinginan untuk terlibat langsung dalam kegiatan pengembangan yang dilakukan agar dapat menambah ilmu pengetahuan tentang alam, memperkenalkan keindahan alam dan budaya yang ada di Balik Bukit Kubu Perahu, dan dapat membuka lapangan pekerjaan bagi masyarakat yang berdomisili di enclave Kubu Perahu.

\section{Pengunjung}

Berdasarkan hasil wawancara dengan pengunjung obyek wisata alam Resort Balik Bukit, persepsi pengunjung terhadap kondisi obyek wisata alam Resort Balik Bukit berbedabeda. Dari segi sarana prasarana dan lingkungan, sebanyak $98 \%$ pengunjung menyatakan baik, akan tetapi pengunjung menyayangkan tidak adanya fasilitas tempat ibadah, penginapan, penjualan souvenir, dan alat outbond. Pengunjung, baik nusantara ataupun mancanegara yang berkunjung ke obyek wisata alam Resort Balik Bukit selain dapat menikmati obyek wisata alam juga dapat membeli dan belajar mebuat kerajinan tangan dari masyarakat yang ada di enclave Kubu Perahu.

\section{Balai Besar Taman Nasional Bukit Barisan Selatan}

Balai Besar Taman Nasional Bukit Barisan Selatan mempunyai rencana bekerjasama dengan instansi lain untuk mengelola dan mengembangkan obyek wisata alam agar lebih baik. Saat ini pihak TNBBS sedang membuat design tapak untuk ditawarkan kepada para stakeholder yang nantinya akan terlibat dalam kegiatan pelaksanaan pengelolaan dan 
pengembangan obyek wisata alam Resort Balik Bukit. Instansi yang nantinya terlibat dalam pengembangan obyek wisata alam Resort Balik Bukit adalah Dinas Kehutanan Kabupaten Lampung Barat dan Dinas Pariwisata dan Lingkungan Hidup Kabupaten Lampung Barat dan BAPPEDA Kabupaten Lampung Barat. Kerjasama yang akan dilakukan diharapkan mencakup pembagian atau kesepakatan dari fungsi dan tanggung jawab yang jelas bagi setiap para pihak sehingga dapat mencapai tujuan pengelolaan dan pengembangan obyek wisata alam yang baik.

\section{Aspek-aspek Manajemen Pengelolaan Obyek Wisata Alam Resort Balik Bukit}

Resort Balik Bukit dikelola oleh Seksi Pengelolaan Taman Nasional Wilayah III Krui (SPTN Wil III Krui), Bidang Pengelolaan Taman Nasional Wilayah II Liwa (BPTN Wil II Liwa), TNBBS dengan luas Resort 23.878 ha. Aspek manajemen yang dilakukan meliputi:

\section{Perencanaan}

Perencanaan yang dilakukan, meliputi: pengkajian wisata, rehabilitasi dan pemeliharaan sarana dan prasarana pendukung, promosi dan pengembangan. Resort Balik Bukit SPTN Wil III Krui, BPTN Wil II TNBBS juga memiliki perencanaan jangka panjang yaitu membuat design tapak dengan tujuan bekerjasama dengan pihak lain dalam pengembangan obyek wisata alam Resort Balik Bukit agar lebih baik.

\section{Pengorganisasian}

Taman Nasional Bukit Barisan Selatan memiliki pengorganisasian yang baik, mulai dari struktur organisasi yang jelas dan dipimpin oleh seorang Kepala Balai Taman Nasional yang membawahi 3 kepala bidang, salah satunya adalah Kepala Bidang Pengelolaan Taman Nasional yang membawahi 2 Kepala Seksi dan Kepala Seksi membawahi 6 Kepala Resort.

Dilihat dari segi sumberdaya manusia (SDM) yang ada, Taman Nasional Bukit Barisan Selatan khusunya Resort Balik Bukit SPTN Wil III Krui BPTN Wil II Liwa memiliki SDM yang cukup memadai dengan 2 Polhut, 2 PEH, 1 Penyuluh, dan 7 Masyarakat Mitra Polhut yang profesional dan berpengalaman. Berdasarkan aplikasi di lapangan para pengelola kurang efektif dalam mengelola obyek wisata alamnya, hal ini dikarenakan minimnya jumlah petugas sementara cakupan wilayah yang harus dikelola cukup luas. Mengingat minimnya jumlah petugas maka diperlukan petugas tambahan terutama Polhut sebanyak 3 Polhut untuk melakukan kegiatan pengelolaan kawasan dan pengembangan obyek wisata alamnya.

\section{Pelaksanaan}

Resort Balik Bukit SPTN Wil III Krui BPTN Wil II Liwa merupakan pelaksana dari pengembangan obyek wisata alam yang telah direncanakan sebelumnya. Kegiatan pelaksanaan pengelolaan dan pengembangan yang dilakukan meliputi:

\section{a. Pengelolaan tiket}

Pengelolaan tiket di Resort Balik Bukit dilakukan oleh staff SPTN Wil III Krui. Tiket masuk kawasan obyek wisata alam Resort Balik Bukit ditentukan berdasarkan Peraturan Pemerintah Republik Indonesia No. 59 Tahun 1998 dengan model DKWA (Daftar Karcis Wisata Alam). Peraturan tersebut berisi tentang harga tiket untuk pengunjung/wisatawan obyek wisata alam Resort Balik Bukit, untuk wisatawan lokal sebesar Rp 1.500 dan untuk wisatawan mancanegara sebesar Rp 15.000.

Pelajar yang ingin mengunjungi obyek wisata alam Resort Balik Bukit dikenakan biaya setengah tarif dari harga tiket wisatawan lokal yaitu Rp 750. Hal ini berlaku jika berkunjung dengan kelompok. Kendaraan yang digunakan oleh pengunjung juga dikenakan tarif tiket, untuk kendaraan roda dua dikenakan tarif sebesar Rp 2.000 sedangkan roda empat $\mathrm{Rp}$ 4.000. Hasil dari karcis yang terjual akan masuk kedalam PNBP (Pendapatan Negara Bukan Pajak). 


\section{b. Pengelolaan parkir}

Umumnya wisatawan mengunjungi obyek wisata alam Resort Balik Bukit menggunakan kendaraan, baik kendaraan roda dua ataupun kendaraan roda empat. Kendaraan yang dibawa oleh pengunjung/wisatawan dapat diparkirkan di tempat parkir yang telah disediakan oleh Resort Balik Bukit yaitu di dekat pondok kerja Resort Balik Bukit, dan didekat bumi perkemahan.

\section{c. Pengelolaan fasilitas wisata}

Fasilitas wisata yang terdapat di Resort Balik Bukit sangat dibutuhkan oleh para pengunjung sebagai penunjang kegiatan wisata yang mereka lakukan, namun belum terawat dengan baik. Hal ini terlihat dari adanya beberapa fasilitas penunjang wisata yang tidak terawat dan memerlukan perbaikan seperti shelter yang sudah rapuh, tangga menara pengamatan yang hilang anak tangganya, jembatan yang kayunya rapuh dan jalur trail wisata yang bebatu tajam.

\section{d. Pengelolaan tempat/sarana Mandi Cuci Kakus (MCK)}

Pengelolaan tempat/sarana MCK dilakukan oleh para petugas yang piket dan dibantu oleh masyarakat. Kegiatan yang dilakukan seperti memeriksa aliran air ke MCK, memeriksa keadaan kabel dan lampu di MCK. MCK dibersihkan oleh masyarakat mitra polhut karena biasanya masyarakat pada sore hari menggunakan bumi perkemahan sebagai tempat bermain sepak bola, dan setelah selesai bermain sepak bola masyarakat meminum air dari aliran air pada pipa air yang mengalir ke lokasi MCK, oleh karena itu masyarakat berperan aktif membantu petugas untuk membersihkan tempat MCK tersebut.

\section{e. Pengelolaan keamanan dan keselamatan}

Pengelolaan keamanan dan keselamatan di Resort Balik Bukit belum efektif, hal ini dikarenakan ada pengunjung yang datang membawa kendaraan terkadang tidak ada yang menjaga kendaraan tersebut. Dengan demikian penyebab belum efektifnya pengelolaan keamanan dan keselamatan di Resort Balik Bukit disebabkan oleh minimnya petugas, sementara petugas Resort Balik Bukit yang ada harus menjalankan tugas lain. Di Resort ini hanya ada 2 Polhut dan 7 Masyarakat Mitra Polhut, selain itu minimnya infrastruktur untuk patrol juga masih minim. Dengan demikian perlu upaya peningkatan pengelolaan keamanan dan keselamatan di Resort Balik Bukit agar para pengunjung yang datang ke obyek wisata alam ini dapat menikmati suasana yang nyaman dan aman.

\section{Pengawasan}

Kepala Balai Besar, Kepala Bidang, Kepala Seksi dan Kepala Resort melakukan pengawasan dan mengevaluasi semua pelaksanaan yang telah dilakukan di lapangan bersamaan dengan dilakukannya pemeliharaan obyek Wisata alam Resort Balik Bukit.

\section{Instansi yang terkait dalam pengembangan Obyek Wisata Alam Resort Balik Bukit}

Resort Balik Bukit dalam pengelolaan dan pengembangannya sebenarnya sudah berekerjasama dengan beberapa instansi seperti dengan Universitas Lampung, Konsorsium Unila-PILI dan Pemerintah Daerah Kabupaten Lampung Barat, namun kerjasama yang dilakukan belum efektif, karena belum berkelanjutan. Saat ini design tapak sedang disusun oleh pihak Taman Nasional agar dapat menarik para pihak untuk bekerjasama mengembangkan obyek wisata alam Resort Balik Bukit.

Resort Balik Bukit terletak di wilayah administrasi Kabupaten Lampung Barat. Kerjasama yang dilakukan dengan Pemerintah Daerah Lampung Barat sampai saat ini tebatas pada koordinasi. Seperti halnya jika ada pengunjung yang datang ke Dinas Pariwisata dan ingin berwisata alam maka Dinas Pariwisata langsung berkoordinasi dengan pihak Taman Nasional dan mengantarkan pengunjung ke lokasi obyek wisata alam Resort Balik Bukit. 


\section{Faktor Strategis yang Mempengaruhi Pengembangan Obyek Wisata Alam (OWA) Resort Balik Bukit Taman Nasional Bukit Barisan Selatan}

Pengembangan obyek wisata alam di Resort Balik Bukit TNBBS dilakukan dengan menggunakan pendekatan faktor internal (kekuatan dan kelemahan) dan eksternal (peluang dan ancaman) yang terkait dengan kondisi yang ada di lapangan. Analisis terhadap kekuatan, kelemahan dan peluang serta ancaman merupakan dasar pertimbangan yang akan mendukung pengembangan ekowisata berbasis masyarakat di Resort Balik Bukit. Faktor strategis eksternal dan internal dapat dilihat pada Tabel 2.

Tabel 2. Faktor internal dan eksternal pengembangan obyek wisata alam Resort Balik Bukit.

\begin{tabular}{|c|c|}
\hline Internal & Eksternal \\
\hline Kekuatan & Peluang \\
\hline $\begin{array}{l}\text { Banyaknya potensi SDA yang dimiliki baik flora } \\
\text { dan fauna }\end{array}$ & $\begin{array}{l}\text { Potensi obyek wisata alam yang potensial } \\
\text { untuk dipromosikan }\end{array}$ \\
\hline o Terdapat bentang adalam yang indah & $\begin{array}{l}\text { Keinginan masyarakat untuk terlibat dalam } \\
\text { pengembangan OWA }\end{array}$ \\
\hline $\begin{array}{l}\text { Adanya kader konservasi dan Pamswakarsa } \\
\text { sebagai modal awal pelibatan masyarakat dalam } \\
\text { pariwisata alam }\end{array}$ & Adanya teknologi untuk promosi \\
\hline ○ Distribusi potensi wisata yang tersebar di lokasi & Banyak permintaan akan wisata alam \\
\hline $\begin{array}{l}\text { - Pengembangan kepariwisataan diakomodasi oleh } \\
\text { BBTNBBS }\end{array}$ & $\begin{array}{l}\text { Adanya keinginan Dinas Pariwisata dan } \\
\text { BAPPEDA Lampung Barat untuk terlibat } \\
\text { dalam pengembangan OWA }\end{array}$ \\
\hline Kelemahan & Ancaman \\
\hline Belum dikelola secara professional & $\begin{array}{l}\text { Pengembangan yang dilakukan dapat } \\
\text { berdampak pada perubahan kualitas } \\
\text { lingkungan }\end{array}$ \\
\hline Promosi yang masih kurang & $\begin{array}{l}\text { Pengembangan ysng dilskukan dapat } \\
\text { berdampak negatif pada flora dan fauna }\end{array}$ \\
\hline $\begin{array}{l}\text { Perizinan (SIMAKSI) harus di Balai Besar } \\
\text { TNBBS }\end{array}$ & Persaingan promosi wisata yang semakin pesat \\
\hline Kualitas dan kuantitas SDM yang masih kurang & $\begin{array}{l}\text { Pengembangan fasilitas wisata dan aktifitas } \\
\text { wisata dapat menyebabkan kerusakan } \\
\text { lingkungan }\end{array}$ \\
\hline Kurangnya dukungan anggaran & $\begin{array}{l}\text { Potensi konflik kepentingan antara pelestarian } \\
\text { dan pemanfaatan untuk pariwisata alam }\end{array}$ \\
\hline
\end{tabular}

Setelah faktor-faktor strategis internal dan eksternal teridentifikasi maka dibuatlah tabel IFAS untuk merumuskan faktor-faktor strategi internal dalam kerangka Strengths dan Weaknesses serta tabel EFAS untuk merumuskann faktor-faktor strategi eksternal dalam kerangka Opportunities dan Threats. Penentuan bobot dan rating masing-masing faktor dilakukan dengan cara berdiskusi dengan Kepala Bidang Pengelolaan Taman Nasional Wilayah II Liwa, Kepala Seksi Pengelolaan Taman Nasional Wilayah III Krui, Kepala Resort Balik Bukit, dan 1 orang Pengendali Ekosistem Hutan. Tabel IFAS dan EFAS dapat dilihat pada Tabel 3 dan 4. 
Tabel 3. IFAS (Internal Strategic Factors Analysis Summary).

\begin{tabular}{|c|c|c|c|}
\hline Faktor strategis internal & Bobot & Rating & Bobot x Rating \\
\hline \multicolumn{4}{|l|}{ Kekuatan } \\
\hline $\begin{array}{l}\text { Banyaknya potensi SDA yang dimiliki baik flora } \\
\text { dan fauna }\end{array}$ & 0,20 & 3 & 0,60 \\
\hline o Terdapat bentang alam yang indah & 0,30 & 3 & 0,90 \\
\hline - Distribusi potensi wisata yang tersebar di lokasi & 0,15 & 4 & 0,60 \\
\hline $\begin{array}{l}\text { Adanya kader konservasi dan Pamswakarsa } \\
\text { sebagai modal awal pelibatan masyarakat dalam } \\
\text { pariwisata alam }\end{array}$ & 0,20 & 3 & 0,60 \\
\hline $\begin{array}{l}\text { - Pengembangan kepariwisataan diakomodasi oleh } \\
\text { BBTNBBS }\end{array}$ & 0,15 & 4 & 0,60 \\
\hline Total & 1,00 & & $\mathbf{3 , 3 0}$ \\
\hline \multicolumn{4}{|l|}{ Kelemahan } \\
\hline$\circ \quad$ Belum dikelola secara professional & 0,15 & 2 & 0,30 \\
\hline$\circ \quad$ Promosi yang masih kurang & 0,20 & 2 & 0,40 \\
\hline Perizinan (SIMAKSI) harus di Balai & 0,15 & 2 & 0,30 \\
\hline Kualitas SDM yang masih kurang & 0,20 & 3 & 0,60 \\
\hline$\circ \quad$ Kurangnya dukungan anggaran & 0,15 & 2 & 0,30 \\
\hline Total & $\mathbf{1 , 0 0}$ & & 2,05 \\
\hline
\end{tabular}

Tabel 4. EFAS (Eksternal Strategic Factors Analysis Summary).

\begin{tabular}{|c|c|c|c|}
\hline Faktor strategis eksternal & Bobot & Rating & Bobot x Rating \\
\hline \multicolumn{4}{|l|}{ Peluang } \\
\hline $\begin{array}{ll} & \text { Potensi obyek wisata alam yang potensial untuk } \\
\text { dipromosikan }\end{array}$ & 0,10 & 2 & 0,20 \\
\hline $\begin{array}{l}\text { Keinginan masyarakat untuk terlibat dalam } \\
\text { pengembangan OWA }\end{array}$ & 0,15 & 3 & 0,45 \\
\hline ○ Adanya teknologi untuk promosi & 0,20 & 3 & 0,60 \\
\hline ○ Banyak permintaan akan wisata alam & 0,25 & 3 & 0,75 \\
\hline $\begin{array}{l}\text { - Adanya keinginan Dinas Pariwisata dan } \\
\text { BAPPEDA Lampung Barat untuk terlibat dalam } \\
\text { pengembangan OWA }\end{array}$ & 0,30 & 4 & 1,20 \\
\hline Total & 1,00 & & 3,20 \\
\hline \multicolumn{4}{|l|}{ Ancaman } \\
\hline $\begin{array}{l}\text { Pengembangan yang dilakukan dapat berdampak } \\
\text { pada perubahan kualitas lingkungan }\end{array}$ & 0,20 & 3 & 0,60 \\
\hline $\begin{array}{l}\text { Pengembangan yang dilakukan dapat berdampak } \\
\text { negatif pada flora dan fauna }\end{array}$ & 0,20 & 2 & 0,40 \\
\hline Persaingan promosi wisata yang semakin pesat & 0,30 & 4 & 1,20 \\
\hline $\begin{array}{l}\text { Pengembangan fasilitas wisata dan aktifitas } \\
\text { wisata dapat menyebabkan kerusakan lingkungan }\end{array}$ & 0,15 & 2 & 0,30 \\
\hline $\begin{array}{l}\text { Potensi konflik kepentingan antara pelestarian } \\
\text { dan pemanfaatan untuk pariwisata alam }\end{array}$ & 0,15 & 3 & 0,45 \\
\hline Total & 1,00 & & 2,95 \\
\hline
\end{tabular}

Bobot dan rating pada masing-masing faktor strategis ditentukan berdasarkan tingkat kepentingan dari faktor tersebut, setelah nilai dari masing-masing faktor ditentukan lalu dilakukan pengalian antara bobot dengan rating. Skor total bobot x rating pada tabel faktor strategis internal kekuatan adalah 3,30 dan skor total faktor strategis internal kelemahan adalah 2,05. Sedangkan Skor total bobot x rating pada tabel faktor strategis eksternal peluang adalah 3,20 dan total skor faktor strategis eksternal ancaman adalah 2,95. 
Setelah total skor dari pengalian bobot dan ratingnya diketahui lalu membuat matriks kuadran untuk mengetahui bagaimana analisis ini bekerja. Matriks kuadran dapat dilihat pada Gambar 1.

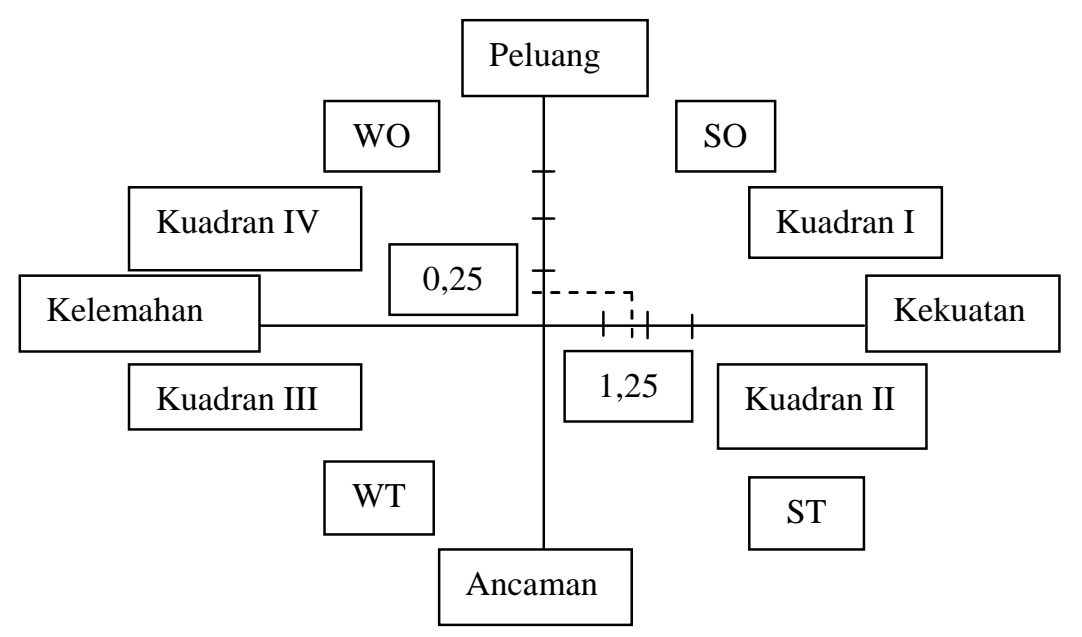

Gambar 1. Matriks kuadran.

Dari matriks kuadran maka dapat dilihat letak koordinat dari strategi yang dihasilkan. Selanjutnya dilakukan analisis lanjut dengan pembuatan matriks SWOT. Matriks SWOT dapat dilihat pada Tabel 5.

Untuk mengetahui strategi mana yang menjadi prioritas untuk dilaksanakan dalam pengembangan obyek wisata alam Resort Balik Bukit maka disusun alternatif strategi dalam analisis SWOT dengan menjumlahkan semua kode pembobotan yang terangkum dalam satu strategi pengelolaan. Alternatif strategi dalam analisis SWOT pengembangan obyek wisata alam di Resort Balik Bukit TNBBS disajikan pada Tabel 6. 
Tabel 5. Matris SWOT.

\begin{tabular}{|c|c|c|}
\hline FAKTOR INTERNAL & KEKUATAN & KELEMAHAN \\
\hline FAKTOR EKSTERNAL & $\begin{array}{ll}\text { O } & \text { Banyaknya potensi SDA yang } \\
\text { dimiliki baik flora dan fauna } \\
\text { - Terdapat bentang adalam yang } \\
\text { indah } \\
\text { D } \\
\text { Distribusi potensi wisata yang } \\
\text { tersebar di lokasi } \\
\text { - Adanya kader konservasi dan } \\
\text { Pamswakarsa sebagai modal awal } \\
\text { pelibatan masyarakat dalam } \\
\text { pariwisata alam } \\
\text { - Pengembangan kepariwisataan } \\
\text { diakomodasi oleh BBTNBBS }\end{array}$ & $\begin{array}{ll}\circ & \text { Belum dikelola secara } \\
& \text { profesional } \\
\circ & \text { Promosi yang masih kurang } \\
\circ & \text { Perizinan (SIMAKSI) harus } \\
\text { di Balai } \\
\circ \quad \text { Kualitas SDM yang masih } \\
\text { kurang } \\
\circ \quad \begin{array}{l}\text { Kurangnya dukungan } \\
\text { anggaran }\end{array}\end{array}$ \\
\hline
\end{tabular}

\section{PELUANG}

- Potensi obyek wisata yang potensial untuk dipromosikan

- Keinginan masyarakat untuk terlibat dalam pengembangan OWA

- Adanya teknologi untuk promosi

- Banyak permintaan akan wisata alam

- Adanya keinginan Dinas Pariwisata dan BAPPEDA Lampung Barat untuk terlibat dalam pengembangan OWA

\section{STRATEGI SO}

- Menjalin kerjasama antara TNBBS dengan masyarakat untuk mejaga dan melestarikan alam serta bekerjasama dengan Dinas Kehutanan, Dinas Pariwisata dan Lingkungan Hidup dan BAPPEDA Lampung Barat

- Adanya teknologi untuk meningkatkan daya promosi kepada pasar wisata

\section{STRATEGI WO}

- Peningkatan kualitas pengelolaan

\begin{tabular}{lll}
\hline ANCAMAN & STRATEGI ST & STRATEGI WT \\
$\circ \begin{array}{l}\text { Pengembangan yang dilakukan dapat } \\
\text { berdampak pada perubahan kualitas } \\
\text { lingkungan }\end{array}$ & $\begin{array}{l}\text { Pengendalian dampak terhadap } \\
\text { lingkungan akibat pengembangan } \\
\text { obyek wisata alam }\end{array}$ & $\begin{array}{l}\text { Pengadaan dan perbaikan } \\
\text { pada fasilitas penujang } \\
\text { wisata }\end{array}$ \\
$\circ \begin{array}{l}\text { Pengembangan yang dilakukan dapat } \\
\text { berdampak negatif pada flora dan fauna }\end{array}$ & & \\
$\circ \quad \begin{array}{l}\text { Persaingan promosi wisata yang semakin } \\
\text { pesat }\end{array}$ & & \\
$\circ \begin{array}{l}\text { Pengembangan fasilitas wisata dan } \\
\text { aktifitas wisata dapat menyebabkan } \\
\text { kerusakan lingkungan }\end{array}$ & \\
Potensi konflik kepentingan antara \\
pelestarian dan pemanfaatan untuk \\
pariwisata alam
\end{tabular}


Tabel 6. Alternatif strategi dalam analisis SWOT pengembangan obyek wisata alam Resort Balik Bukit TNBBS.

\begin{tabular}{|c|c|c|c|}
\hline Strategi & Kode Pembobotan & Total & Prioritas \\
\hline \multicolumn{4}{|l|}{ SO } \\
\hline $\begin{array}{l}\text { 1. Menjalin kerjasama antara TNBBS } \\
\text { dengan masyarakat, Dinas Kehutanan, } \\
\text { Dinas Pariwisata dan Lingkungan }\end{array}$ & $\begin{array}{l}\mathrm{S} 1+\mathrm{S} 2+\mathrm{S} 3+\mathrm{S} 4+\mathrm{S} 5+\mathrm{O} 1+\mathrm{O} 2+ \\
\mathrm{O} 3+\mathrm{O} 4+\mathrm{O} 5\end{array}$ & 6,50 & 1 \\
\hline $\begin{array}{l}\text { Hidup serta BAPPEDA dalam } \\
\text { pengembangan obyek wisata alam } \\
\text { Resort Balik Bukit }\end{array}$ & & & \\
\hline $\begin{array}{l}\text { 2. Adanya teknologi untuk meningkatkan } \\
\text { daya promosi kepada pasar wisata }\end{array}$ & $\mathrm{S} 1+\mathrm{S} 2+\mathrm{S} 3+\mathrm{S} 5+\mathrm{O} 3+\mathrm{O} 4+\mathrm{O} 5$ & 5,25 & 2 \\
\hline \multicolumn{4}{|l|}{ ST } \\
\hline 1. Pengendalian dampak terhadap & $\mathrm{S} 5+\mathrm{T} 1+\mathrm{T} 2$ & 1,60 & 4 \\
\hline $\begin{array}{l}\text { lingkungan akibat pengembangan } \\
\text { obyek wisata alam }\end{array}$ & & & \\
\hline \multicolumn{4}{|l|}{ WO } \\
\hline 1. Peningkatan kualitas pengelolaan & $\mathrm{W} 2+\mathrm{W} 3+\mathrm{W} 4+\mathrm{O} 2+\mathrm{O} 5$ & 2,95 & 3 \\
\hline \multicolumn{4}{|l|}{ WT } \\
\hline $\begin{array}{l}\text { 1. Pengadaan dan perbaikan pada fasilitas } \\
\text { penujang wisata }\end{array}$ & $\mathrm{W} 1+\mathrm{T} 4$ & 0,60 & 5 \\
\hline
\end{tabular}

Sumber: Data primer penelitian, 2013

Berdasarkan analisis SWOT terhadap faktor internal dan faktor eksternal maka disusun strategi pengembangan obyek wisata alam Resort Balik Bukit TNBBS, yaitu:

1. Menjalin kerjasama antara TNBBS dengan masyarakat, Dinas Kehutanan, Dinas Pariwisata dan Lingkungan Hidup serta BAPPEDA dalam pengembangan obyek wisata alam Resort Balik Bukit.

2. Adanya teknologi untuk meningkatkan daya promosi kepada pasar wisata.

3. Peningkatan kualitas pengelolaan.

4. Pengendalian dampak terhadap lingkungan akibat pengembangan obyek wisata alam.

5. Pengadaan dan perbaikan pada fasilitas penujang wisata.

\section{SIMPULAN DAN SARAN}

\section{Simpulan}

1. Potensi sumberdaya wisata Resort Balik Bukit yang dapat dijadikan daya tarik wisata berupa bentang alamnya, seperti Air Terjun Sepapa Kanan Sepapa Kiri, Way Asahan, Sungai Way Sepapa, Ekosistem Hutan Hujan Pegunungan Primer, Demplot, Flora dan Fauna, Pemandangan Alam, dan Batu Balok.

2. Potensi sumberdaya manusia yang dapat menunjang kegiatan pengembangan obyek wisata alam Resort Balik Bukit meliputi kemampuan masyarakat dalam membuat kerajinan tangan.

3. Manajemen pengelolaan obyek wisata alam Resort Balik Bukit dilakukan dengan cukup baik oleh pihak Resort Balik Bukit SPTN III Wil Krui BPTN II Wil II liwa TNBBS, meliputi: perencanaan, pengorganisasian dan pengawasan, akan tetapi dengan minimnya petugas yang ada di Resort Balik Bukit pengelolaan obyek wisata alamnya kurang efektif karena dengan jumlah petugas tersebut tidak seimbang dengan wilayah yang cukup luas.

4. Berdasarkan faktor internal dan eksternal maka strategi paling utama untuk diterapkan dalam pengembangan obyek wisata alam Resort Balik Bukit TNBBS adalah strategi menggunakan kekuatan untuk memanfaatkan peluang (Strengths-Oportunities), yaitu Menjalin kerjasama antara TNBBS dengan masyarakat untuk mejaga dan melestarikan 
alam serta bekerjasama dengan Dinas Kehutanan, Dinas Pariwisata dan Lingkungan Hidup dan BAPPEDA Lampung Barat.

\section{Saran}

Salah satu alternatif pengembangan obyek wisata alam Resort Balik Bukit TNBBS adalah menjalin kerjasama dengan instansi-instansi lain seperti Dinas Pariwisata, dan BAPPEDA Kabupaten Lampung Barat serta memperbaiki fasilitas-fasilitas wisata yang sudah rusak.

\section{DAFTAR PUSTAKA}

Andayani. N. L. H. 2007. Pengembangan obyek wisata Desa Tihingan, Kecamatan Banjarangkan, Kabupaten Klungkung. Jurnal Manajemem Pariwisata 7(1). STIE Triatma Jaya.

Arikunto S. 2002. Prosedur Penelitian. Buku. 54-60. Rineka Cipta, Jakarta.

Balai Taman Nasional Bukit Barisan Selatan. 2007. Masterplan pengembangan obyek wisata alam di Kawasan Taman Nasional Bukit Barisan Selatan. Buku. 65-78. Kota Agung, BTNBBS.

Nugraheni D \& F Yusman. 2013. Kajian pengembangan Kawasan Wisata Pantai Suwuk Kabupaten Ditinjau dari segi pengelolaan dan pemasarannya. Jurnal Teknik PWK 2(1): 1-14. Universitas Diponegoro.

Nurdianti A, S Ningsih \& M Sutri. 2013. Potensi pengembangan wisata alam di Habitat Maleo(Macricephalon maleo) Taman Nasional Lore Lindung Bidang Pengelolaan Wilayah (BPW) I Saluki Kecamatan Sigi. Jurnal Warta Rimba 1(1): 1-8. Universitas Tadulako.

Qomariah L. 2009. Pengembangan ekowisata berbasis masyarakat Di Taman Nasional Meru Betiri (Studi Kasus Blog Rajegwesi SPTN I Sarongan). Skripsi. 38-42. Institut Pertanian Bogor. Bogor.

Rangkuti F. 2006. Analisis SWOT teknik membedah kasus bisnis. Buku. 23-26. Gramedia Pustaka Utama. Jakarta.

Rachmawati E. 2010. Sistem sosial pengembangan Wisata Alam di Kawasan Gunung Salak Endah. Skripsi. Institut Pertanian Bogor. Bogor.

Umardiono A. 2011. Pengembangan obyek wisata Taman Nasional Laut Kepulauan Karimun Jawa. Jurnal Masyarakat, kebudayaan dan politik (MKP). 24(3):192-200. Universitas Airlangga. 